\title{
Heme Oxygenase-1 May Affect Cell Signalling via Modulation of Ganglioside Composition
}

\author{
Václav Šmíd (D), ${ }^{1,2}$ Jakub Šuk $\mathbb{D}^{1}{ }^{1}$ Neli Kachamakova-Trojanowska, ${ }^{3,4}$ Jana Jašprová, ${ }^{1}$ \\ Petra Valášková $\left(\mathbb{D},{ }^{1}\right.$ Alicja Józkowicz $\left(\mathbb{D},{ }^{3}\right.$ Józef Dulak, ${ }^{3}$ František Šmíd, ${ }^{1}$ Libor Vítek $\mathbb{D}^{1,2}$ \\ and Lucie Muchová (D) \\ ${ }^{1}$ Institute of Medical Biochemistry and Laboratory Diagnostics, 1st Faculty of Medicine and General University Hospital in Prague, \\ Charles University, Katerinska 32, 12108 Prague, Czech Republic \\ ${ }^{2} 4$ th Department of Internal Medicine, 1st Faculty of Medicine and General University Hospital in Prague, Charles University, \\ U Nemocnice 499/2, 12801 Prague, Czech Republic \\ ${ }^{3}$ Department of Medical Biotechnology, Faculty of Biochemistry, Biophysics and Biotechnology, Jagiellonian University, \\ 7 Gronostajowa St., 30-387 Krakow, Poland \\ ${ }^{4}$ Malopolska Centre for Biotechnology, Jagiellonian University, Gronostajowa str 7a, 30-387 Krakow, Poland
}

Correspondence should be addressed to Lucie Muchová; lucie.muchova@lf1.cuni.cz

Received 14 May 2018; Revised 28 July 2018; Accepted 5 August 2018; Published 19 September 2018

Academic Editor: Daniele Vergara

Copyright ( 2018 Václav Šmíd et al. This is an open access article distributed under the Creative Commons Attribution License, which permits unrestricted use, distribution, and reproduction in any medium, provided the original work is properly cited.

Heme oxygenase 1 (Hmox1), a ubiquitous enzyme degrading heme to carbon monoxide, iron, and biliverdin, is one of the cytoprotective enzymes induced in response to a variety of stimuli, including cellular oxidative stress. Gangliosides, sialic acidcontaining glycosphingolipids expressed in all cells, are involved in cell recognition, signalling, and membrane stabilization. Their expression is often altered under many pathological and physiological conditions including cell death, proliferation, and differentiation. The aim of this study was to assess the possible role of Hmoxl in ganglioside metabolism in relation to oxidative stress. The content of liver and brain gangliosides, their cellular distribution, and mRNA as well as protein expression of key glycosyltransferases were determined in Hmoxl knockout mice as well as their wild-type littermates. To elucidate the possible underlying mechanisms between Hmox1 and ganglioside metabolism, hepatoblastoma HepG2 and neuroblastoma SH-SY5Y cell lines were used for in vitro experiments. Mice lacking Hmoxl exhibited a significant increase in concentrations of liver and brain gangliosides and in mRNA expression of the key enzymes of ganglioside metabolism. A marked shift of GM1 ganglioside from the subsinusoidal part of the intracellular compartment into sinusoidal membranes of hepatocytes was shown in Hmox 1 knockout mice. Induction of oxidative stress by chenodeoxycholic acid in vitro resulted in a significant increase in GM3, GM2, and GD1a gangliosides in SH-SY5Y cells and GM3 and GM2 in the HepG2 cell line. These changes were abolished with administration of bilirubin, a potent antioxidant agent. These observations were closely related to oxidative stress-mediated changes in sialyltransferase expression regulated at least partially through the protein kinase $\mathrm{C}$ pathway. We conclude that oxidative stress is an important factor modulating synthesis and distribution of gangliosides in vivo and in vitro which might affect ganglioside signalling in higher organisms.

\section{Introduction}

Heme oxygenase $1(\operatorname{Hmox} 1)$ is a highly inducible antioxidant and cytoprotective enzyme in the heme catabolic pathway generating equimolar amounts of iron, carbon monoxide, and biliverdin which is immediately reduced to bilirubin [1]. Hmoxl activity-also due to the effect of its bioactive products-affects pathophysiology of many neurologic, cardiovascular, and pulmonary diseases [2-4]. In the liver, Hmoxl plays an important role in hepatic fat accumulation, fibrogenesis, ischemia-reperfusion, and oxidative injury [5]. Moreover, upon Hmoxl knockout, the cells and/or animals become more vulnerable to oxidative stress. Free radical formation as well as oxidative stress- 
associated cytotoxicity are increased in $H \operatorname{mox} 1$ knockouts due to reduced antioxidant bilirubin and vasoactive carbon monoxide formation, disruption of iron homeostasis, and accumulation of prooxidative heme [6]. Due to iron accumulation, liver is one of the tissues most affected by an increased oxidative stress in Hmox 1 knockout mice and increased lipid peroxidation, fibrosis, and hepatic injury have been described in these animals [5]. Furthermore, an increase in some key cytoprotective genes such as $\mathrm{NAD}(\mathrm{P}) \mathrm{H}$ dehydrogenase quinone 1 and glutathione S-transferase P1 and marked decrease in peroxyl radical scavenging activity have been described in Hmox1 knockouts even under basal (unstimulated) conditions [7]. Bilirubin per se is considered a potent endogenous antioxidant protecting against diseases associated with oxidative stress [8] and counteracting harmful effects of various prooxidants including hydrophobic bile acids (BA) on cells and tissues [9]. In fact, both bilirubin and BA are accumulated in plasma and tissues during cholestasis and while BA are responsible for increased lipid peroxidation and oxidative liver damage, bilirubin has a protective effect [10].

Gangliosides are ubiquitously found in all tissues, but most abundantly in the nervous system [11]. They substantially influence the organization of the membrane and the function of specific membrane-associated proteins due to lipid-lipid and lipid-protein lateral interactions [12]. In the brain, ganglioside expression correlates with neurogenesis, synaptogenesis, synaptic transmission, and cell proliferation [13, 14].

It is known that gangliosides form so called caveolae or "detergent resistant microdomains" (DRM), which are crucial elements for cell-cell recognition, adhesion, and especially membrane stabilization $[15,16]$. There is also evidence that caveolin-1, an important component of caveolae, interacts with Hmox1, modulates its activity, and can act as a natural competitive inhibitor of Hmoxl with heme [17]. Moreover, gangliosides have been found to inhibit hydroxyl radical formation in vitro [18] and also modulate ROS formation in human leukocytes [19] and neuronal cells [20].

Despite the close relationship of gangliosides and Hmox1 in DRM, there are only few reports discussing the possible role of Hmoxl or oxidative stress in ganglioside metabolism [21, 22]. The aim of this study was to assess the role of Hmoxl knockout and associated oxidative stress on ganglioside metabolism and to identify the possible underlying mechanisms.

\section{Materials and Methods}

2.1. Materials. Paraformaldehyde, biotin, bovine serum albumin (BSA), phorbol 12-myristate 13-acetate (protein kinase C (PKC) activator), Ro 31-0432 (PKC inhibitor), chenodeoxycholic acid (CDCA), diaminobenzidine tetrahydrochloride tablets, NADPH, and sulfosalicylic acid were supplied by Sigma-Aldrich (St. Louis, MO, USA); avidin was obtained from Fluka (Buchs, Switzerland), the cholera toxin B subunit (CTB) peroxidase conjugated came from List Biological Laboratories (CA, USA), and the HPTLC silica-gel plates came from Merck (Darmstadt, Germany). Cell plates were supplied by Corning (NY, USA). The TaqMan ${ }^{\circledR}$ Gene Expression Master Mix, High-Capacity RNA-to-cDNA Kit, and the TaqMan Gene Expression Assay kit for mouse and human genes were obtained from Life Technologies (Carlsbad, CA, USA). The QIAshredder kit and RNeasy Plus Mini Kit were supplied by Qiagen (USA). All other chemicals were purchased locally from Penta (Prague, Czech Republic).

2.2. Animals. Hmox1 $1^{-1-}(n=9 ; \mathrm{KO}-$ knockout $)$ mice and $H_{m o x} 1^{+/+}$( $n=6$; Wt-wild type) littermates (C57Bl/6xFVB, 8 -week-old males) were used for all the experiments. Breeding heterozygote pairs of Hmoxl-deficient mice were initially kindly provided by Anupam Agarwal, University of Alabama (Birmingham, AL). The Hmox1 $1^{-/-}$strain poorly breeds on pure $\mathrm{C} 57 / \mathrm{Bl} 6$ background (5.1\% of expected $\mathrm{Hmox}^{-1-}$ pups) and therefore is maintained on mixed $\mathrm{C} 57 / \mathrm{Bl} 6 \times \mathrm{FVB}$ background $\left(20.1 \%\right.$ of expected $H \mathrm{mox}^{-/-}$pups, when $H$ mox ${ }^{-/-}$ males are crossed with $\mathrm{Hmox}^{+/-}$females) [23]. All Hmox1 ${ }^{+/+}$ controls were C57/Bl6xFVB littermates from the same breeders used to obtain $H \operatorname{mox} 1^{-1-}$ mice. They had free access to food and water and were kept in individually ventilated cages with a 12:12 day/night cycle, under a specific pathogen-free regime. All aspects of the study met the accepted criteria of experimental use of laboratory animals, and all protocols were approved by the Animal Research Committee of the 1st Faculty of Medicine, Charles University, Prague, Czech Republic, and by the 1st Local Ethics Committee for Animal Research, Krakow, Poland.

2.3. Tissue Preparation. Mice were intraperitoneally anesthetized with ketamine $(90 \mathrm{mg} / \mathrm{kg})$ and xylazine $(10 \mathrm{mg} / \mathrm{kg})$ and sacrificed by cervical dislocation at day 5 . The inferior vena cava was cannulated through laparotomy, and blood samples were collected, transferred to EDTA-containing tubes, mixed, and placed on ice. An aliquot was centrifuged to separate out the plasma. The livers and brains were then harvested and weighed. Pieces of liver tissues were appropriately processed for further biochemical and histochemical analyses (see below). For quantitative histochemical analysis of GM1 ganglioside, the liver specimens were collected using a systematic uniform random sampling method [24].

For the RNA analysis, $100 \mathrm{mg}$ of tissue was immediately placed in $1.5 \mathrm{~mL}$ microcentrifuge tubes containing RNAlater (Qiagen, Valencia, CA, USA). The tubes were stored at $-80^{\circ} \mathrm{C}$ until total RNA isolation.

2.4. Extraction and TLC Densitometry of Liver and Brain Gangliosides. The chloroform-methanol extraction of gangliosides from the liver tissue was used-the procedure previously described by Majer et al. [25] — and gangliosides were finally purified on a small silica gel column [26]. Brain gangliosides were isolated as described previously [27, 28]. All ganglioside samples were separated in a solvent system (chloroform/methanol/0.2\% aqueous $\mathrm{CaCl}_{2}, 55 / 45 / 10, v / v / v$ ) and detected with resorcinol-HCl reagent. The densitometry was performed according to Majer et al. [25] using a CATS3 Software, CAMAG (Switzerland).

GSL are abbreviated according to recommendations of the IUPAC-IUB Commission on Biochemical Nomenclature [29]: glycosyltransferases: GlcT, UDP-glucose ceramide 
glucosyltransferase; GalTI, UDP-Gal:betaGlcNAc beta-1,4galactosyltransferase; ST3GalV (GM3 synthase), ST3 betagalactoside alpha-2,3-sialyltransferase 5; ST8SiaI (GD3 synthase), ST8 alpha- $N$-acetylneuraminide alpha-2,8-sialyltransferase 1; B4GalNTI (GM2/GD2 synthase), beta-1,4-Nacetyl-galactosaminyltransferase 1; and B3GalTIV (GM1 synthase), UDP-Gal:betaGlcNAc beta 1,3-galactosyltransferase.

2.5. GM1 Histochemistry. GM1 was determined using a modified procedure according to Jirkovská et al. [30]. In brief, $4 \%$ formaldehyde was freshly prepared by depolymerization of paraformaldehyde $(\mathrm{pH}=7.2)$. Frozen $6 \mu \mathrm{m}$ thin sections were first fixed in dry cold acetone $\left(-20^{\circ} \mathrm{C}\right)$ for $15 \mathrm{~min}$ and then in $4 \%$ freshly prepared paraformaldehyde for $5 \mathrm{~min}$. Endogenous peroxidase activity was blocked by incubation for $15 \mathrm{~min}$ in phosphate-buffered saline (PBS) supplemented by $1 \% \mathrm{H}_{2} \mathrm{O}_{2}$ and $0.1 \%$ sodium azide. Endogenous biotin was blocked by means of a DakoCytomation blocking kit (DakoCytomation, Denmark). In order to block nonspecific binding, sections were treated with 3\% BSA in PBS for $15 \mathrm{~min}$. GM1 ganglioside was detected in liver sections using CTB biotin labelled (Sigma, USA), diluted 1:300 in PBS, plus $3 \%$ BSA at $8^{\circ} \mathrm{C}$ for $16.5 \mathrm{~h}$, followed with streptavidin-peroxidase polymer at room temperature for $1 \mathrm{~h}$. Peroxidase activity was visualized with diaminobenzidine tetrahydrochloride for $20 \mathrm{~min}$ in the dark. Sections were mounted in mounting medium Dako S3025 (Dako North America, CA, USA).

Two negative control tests were performed for each group. First, CTB was omitted in immunohistochemical staining. Second, fixed sections were extracted with chloroform:methanol 2:1 at room temperature for 30 minutes followed by standard immunohistochemical staining.

2.6. Densitometric Analysis of GM1 Ganglioside in Sinusoidal Membrane and Adjacent Cytoplasm Areas. Six liver specimens were used from each animal. One section from each specimen was used for GM1 ganglioside detection with CTB as described above. From each section, four hepatic lobules with a clearly discernible central vein were selected. In each lobule, one measuring frame in the central lobular zone III and one measuring frame in the corresponding peripheral lobular zone I were selected for analysis. In each frame, 15 areas of sinusoidal surface and 15 areas of adjacent hepatocyte cytoplasm were selected by the stratified random sampling method [24] and marked out. The reaction product was quantified as the mean optical density of the analyzed areas (determined by the densitometric program ACC 6.0, SOFO, Czech Republic) at objective magnification of $40 \mathrm{x}$ $(\mathrm{NA}=0.7)$. The ratios of densities measured in the sinusoidal membrane and subsinusoidal intracellular compartment were measured and compared together (sin/int).

2.7. Cell Culture Experiments. Human neuroblastoma cell line SH-SY5Y (ATCC, Manassas, VA, USA) was cultured in the Minimum Essential Medium Eagle (MEM) and Ham's F-12 medium $(1: 1, v / v)$ with $15 \%$ of fetal bovine serum and human hepatoblastoma cell line HepG2 (ATCC, Manassas, VA, USA) in MEM with $10 \%$ of fetal bovine serum in a humidified atmosphere (containing $5 \% \quad \mathrm{CO}_{2}$ and $37^{\circ} \mathrm{C}$ ). Authentication of used cell lines was confirmed by an independent laboratory using a method based on an accredited short tandem repeat analysis.

Cells were seeded onto 6-well plates (Corning, NY, USA) at a concentration of 50,000 cells per $1 \mathrm{~cm}^{2}$ and treated with CDCA and bilirubin for $4 \mathrm{~h}$. SH-SY5Y cells were also treated with PKC activator (phorbol 12-myristate 13-acetate) or PKC inhibitor (Ro 31-0432) for $4 \mathrm{~h}$. After the incubation period, cells were harvested into the lysis buffer and stored at $-80^{\circ} \mathrm{C}$ for further experiments.

2.8. Measurement of Intracellular ROS Production. ROS production was determined using a fluorescent probe 5-(and-6)chloromethyl-2' $2^{\prime}$-dichlorodihydrofluorescein diacetate acetyl ester (CM-H 2 DCFDA, Life Technologies, USA). Briefly, SH-SY5Y cells were grown in 12-well plates to $80 \%$ confluence. Cells were then incubated with CDCA and/or antioxidant (bilirubin) for $24 \mathrm{~h}$. After the incubation, the cells were washed twice with PBS and loaded with $10 \mu \mathrm{M}$ $\mathrm{CM}-\mathrm{H} 2 \mathrm{DCFDA}$ at $37^{\circ} \mathrm{C}$ for $30 \mathrm{~min}$ in the dark, then washed with PBS to remove excess dye. Fluorescence was measured using $485 \mathrm{~nm}$ excitation and $540 \mathrm{~nm}$ emission wavelengths in microplate reader (Synergy HTX, BioTek, USA). Cells were then lysed with Cell Lysis Buffer (Cell Signaling Technology, USA), and protein concentration was measured using DC Protein Assay (Bio-Rad, USA) according to the manufacturer's instruction. Data were normalized to protein content and expressed as \% of controls.

2.9. Lipid Peroxidation. Lipid peroxidation was measured according to the method by Vreman et al. [31]. Twenty microliters of $10 \%$ liver or brain sonicates in $0.1 \mathrm{M}$ phosphate buffer, $\mathrm{pH}=7.4$, were incubated at $37^{\circ} \mathrm{C}$ with $100 \mu \mathrm{M}$ ascorbate $(80 \mu \mathrm{L})$ and $6 \mu \mathrm{M} \mathrm{Fe}^{2+}(0.5 \mu \mathrm{L})$ in a septum-sealed vial. Butylated hydroxytoluene $(10 \mu \mathrm{M})$ was added to the blank reaction. The reaction was terminated by adding $2 \mu \mathrm{L}$ of $60 \%$ sulfosalicylic acid. CO produced into the vial headspace was quantified by gas chromatography with a reduction gas analyzer (Peak Laboratories LLC, Mountain View, CA, USA). The amount of CO produced served as an index of lipid peroxidation, was measured as picomoles of $\mathrm{CO}$ per hour per milligram of fresh tissue, and was expressed as \% of control.

2.10. Western Blotting. Cells grown to $60 \%$ confluency were lysed using RIPA buffer supplemented with phosphatase and protease inhibitors (Protease Inhibitor Mix G and Phosphatase Inhibitor Mix I, Serva, Heidelberg, Germany). Samples were separated by SDS-PAGE on $12 \%$ polyacrylamide gel and then transferred to nitrocellulose membrane (Bio-Rad Laboratories, Hercules, CA, USA). After blocking in Tween-PBS with 5\% BSA (Sigma-Aldrich, St. Louis, MO, USA) for at least $1.5 \mathrm{~h}$, membranes were incubated with GM3 synthase and GM2/GD2 synthase antibody (1:2000; Santa Cruz sc-365329 and sc-376505, Dallas, TX, USA), or $\beta$-actin (1:2000; Cell Signaling Technology, Danvers, MA, USA) overnight at $4^{\circ} \mathrm{C}$. After washing, membranes were incubated with anti-mouse $\mathrm{m}-\mathrm{IgG} \kappa$ BP-HRP (Santa Cruz 

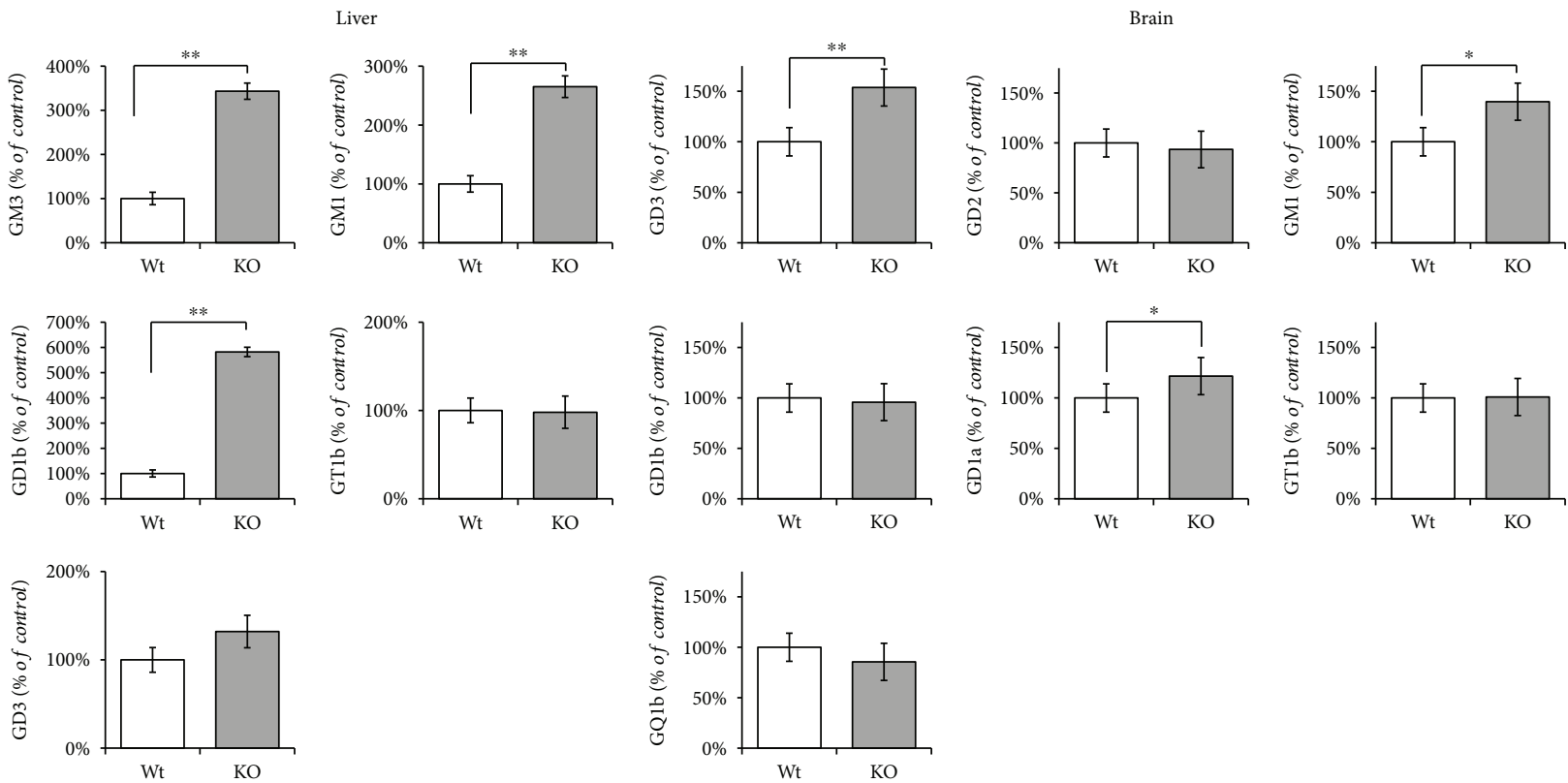

(a)

(b)

FIgURE 1: The impact of Hmox1 knockout on ganglioside composition in mouse (a) liver and (b) brain. Isolated hepatic (a) and brain (b) gangliosides were separated in a solvent system and analyzed by a densitometric method after TLC separation and detection using resorcinol-HCl reagent. Values are expressed as \% of control and represent mean SD. Wt: wild-type $(n=6)$; KO: Hmox1 knockout $(n=9)$. ${ }^{*} P<0.05$ and ${ }^{* *} P<0.01$.

sc-516102, Dallas, TX, USA) for $1 \mathrm{~h}$. Immunocomplexes on the membranes were visualized with ECL Western Blotting Detection Reagents (Cell Signaling Technology) using an Odyssey infrared imaging system (LI-COR Biosciences, Lincoln, NE, USA).

2.11. Quantitative Real-Time PCR. The liver samples were stored frozen at $-80^{\circ} \mathrm{C}$ in RNAlater (Sigma-Aldrich, St. Louis, USA), and total RNA was isolated using a Qiagen RNAeasy Plus kit and QIAshredder (Qiagen, USA). Cell culture samples were stored in lysis buffer at $-80^{\circ} \mathrm{C}$, and total RNA was isolated using PerfectPure RNA Cell Kit (5Prime, USA). A High-Capacity cDNA Reverse Transcription Kit (Life Technologies, Carlsbad, CA, USA) was used to generate cDNA. Quantitative real-time PCR was performed using TaqMan ${ }^{\circledR}$ Gene Expression Assay Kit (Life Technologies, Carlsbad, CA, USA) for the following genes: GlcT (Hs00234293_m1), GalTI (Hs00191135_m1), GM3 synthase (St3GalV, Mm00488237_m1, and Hs01105379_m1), GD3 synthase (STSia8, Mm00456915_m1, and Hs00268157_m1), GM2/GD2 synthase (B4GalNT1, Mm00484653_m1, and Hs01110791_g1), and GM1 synthase (B3GalT4, Mm00546324_s1, and Hs00534104_s1), all provided by Life Technologies (Carlsbad, CA, USA). The data were normalized to HPRT and expressed as percent of control levels.

2.12. Statistical Analysis. Normally distributed data are presented as mean $\pm \mathrm{SD}$ and analyzed by the Student $t$-test. The Mann-Whitney $U$ test or Kruskal-Wallis test were used in skewed data. Differences with $P<0.05$ were considered significant.

\section{Results}

3.1. The Impact of Hmox1 Knockout on the Liver and Brain Ganglioside Content. To investigate the role of Hmoxl knockout on the ganglioside pattern, we measured changes in ganglioside composition in the liver as well as the brain, the tissue with the highest glycolipid content in vivo. As the ganglioside spectra differ within specific tissues, only major gangliosides and representatives of two main biosynthetic pathways, $a$ - and $b$-series, were determined.

In the liver, mice lacking Hmoxl exhibited marked increases in the concentrations of individual gangliosides. Specifically, Hmox 1 knockout led to a significant increase in GM3 $(343 \pm 76 \%, P<0.001)$ and GM1 $(265 \pm 62 \%$, $P<0.001)$ representing $a$-series, and GD1b $(582 \pm 176 \%$, $P<0.001$ ) from $b$-series of gangliosides (Figure 1(a)).

In the brain, the most abundant ganglioside was GD1a in both wild-type as well as knockout animals. Together with GM1, GD1a content was significantly higher (GD1a 122\% vs. Wt, $P<0.05$; GM1 $140 \%$ vs. Wt, $P<0.05)$ in Hmox 1 knockout mice as compared to wild types. The other two major brain gangliosides (GM3, GT1b) stayed unchanged after Hmox1 knockout. The amount of minor GD3 ganglioside was also significantly increased $(154 \%$ vs. Wt, $P<0.01)$ (Figure 1(b)). The scheme of de novo biosynthesis of the oligosaccharide moieties of gangliosides is illustrated in Figure 2.

To confirm the level of oxidative stress in Hmox 1 knockouts, we measured the extent of lipid peroxidation in liver and brain tissue homogenates. Importantly, liver lipid peroxidation was increased in Hmox 1 knockout mice as compared to controls $\left(155 \% \pm 51 \% \mathrm{Hmox}^{-/-}, n=7\right.$, vs. $100 \% \pm 46 \%$ 


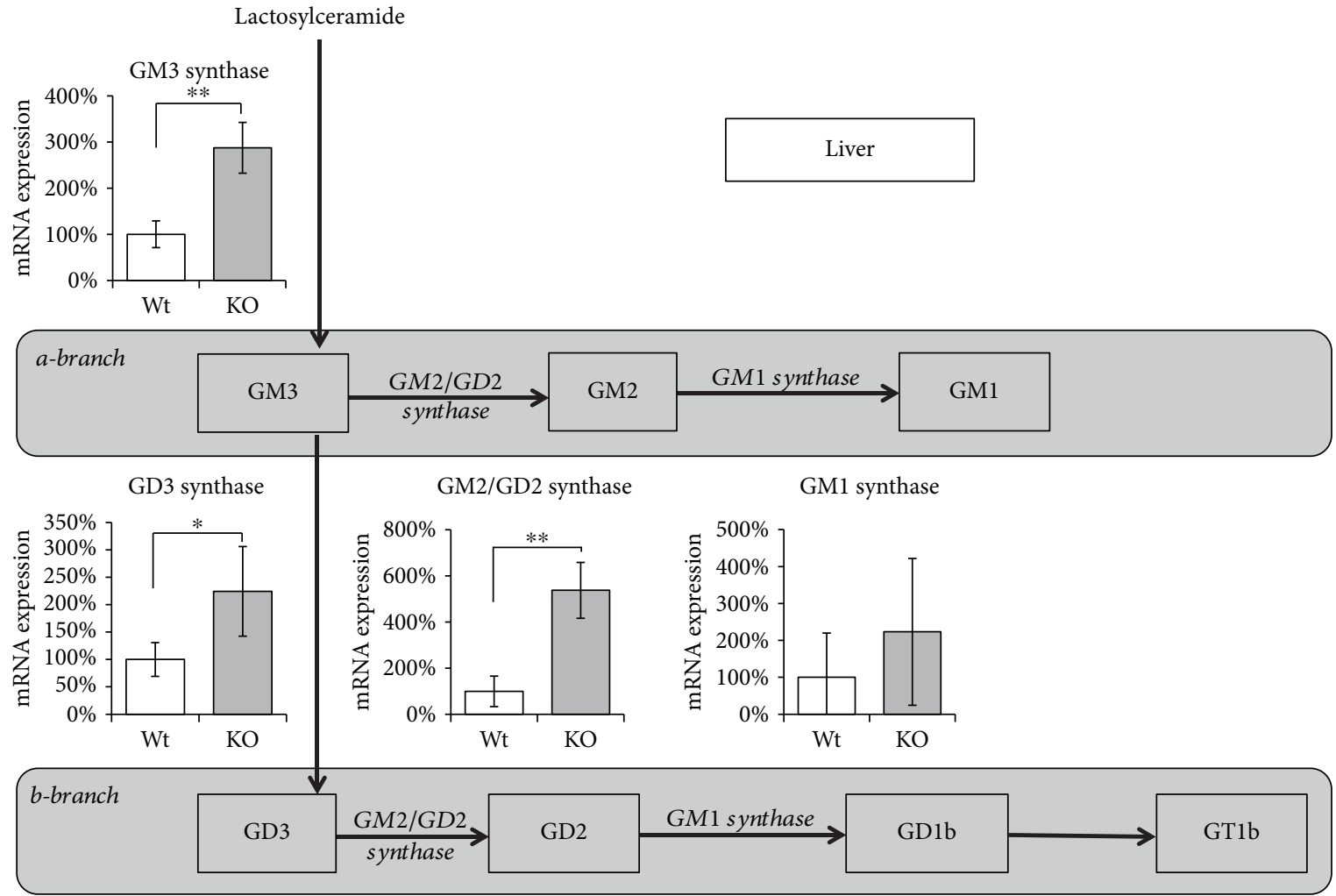

(a)

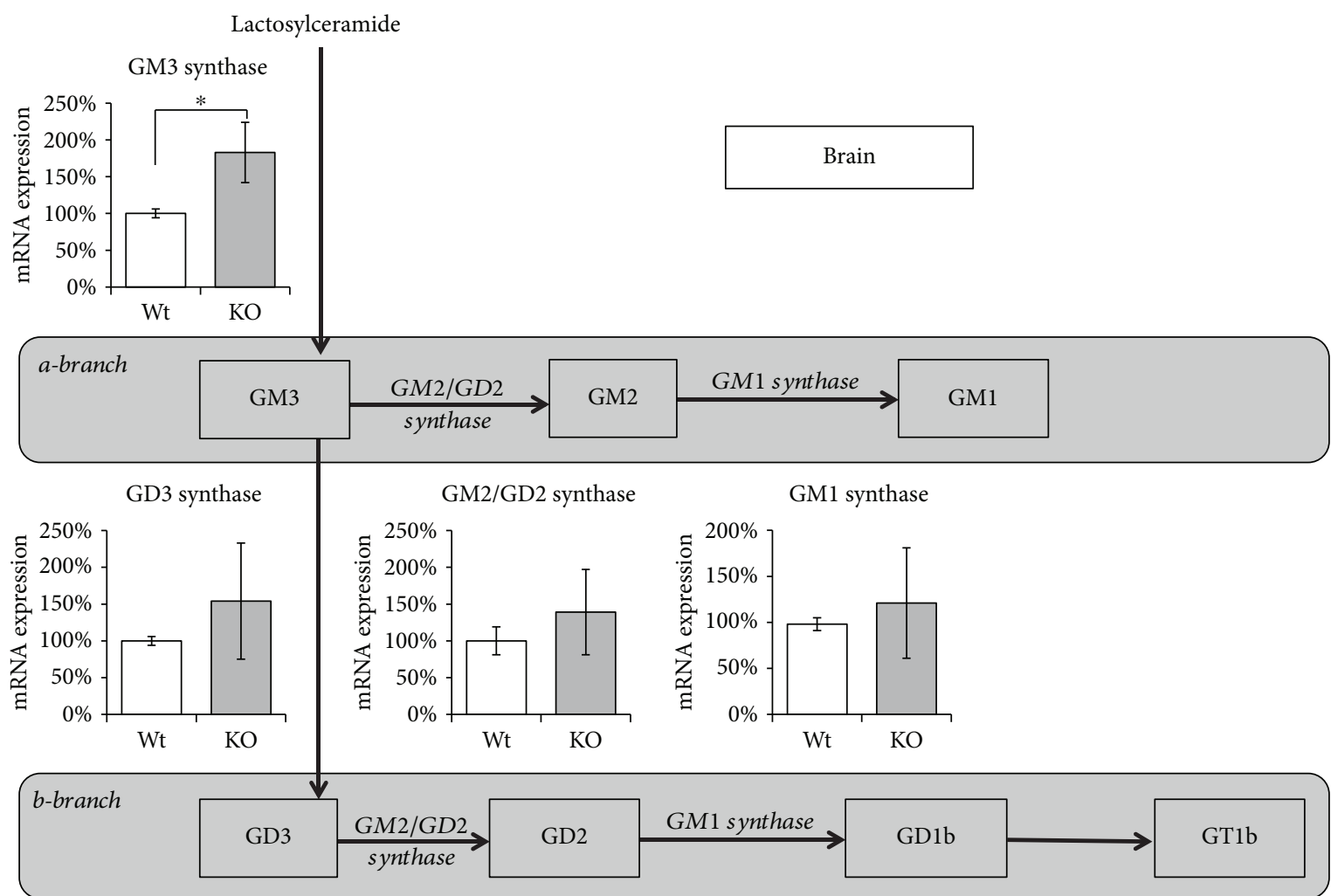

(b)

FIGURE 2: Hmox1 knockout leads to changes in sialyltransferase expression in the liver and brain. Relative mRNA expression of the key enzymes in ganglioside synthesis was measured in the liver (a) and brain (b) tissues of wild-type (Wt) and Hmoxl knockout (KO) animals. Values are expressed as $\%$ of control. Wt: wild-type $(n=6)$; KO: Hmoxl knockout $(n=9) .{ }^{*} P<0.01 ;{ }^{* *} P<0.001$. 

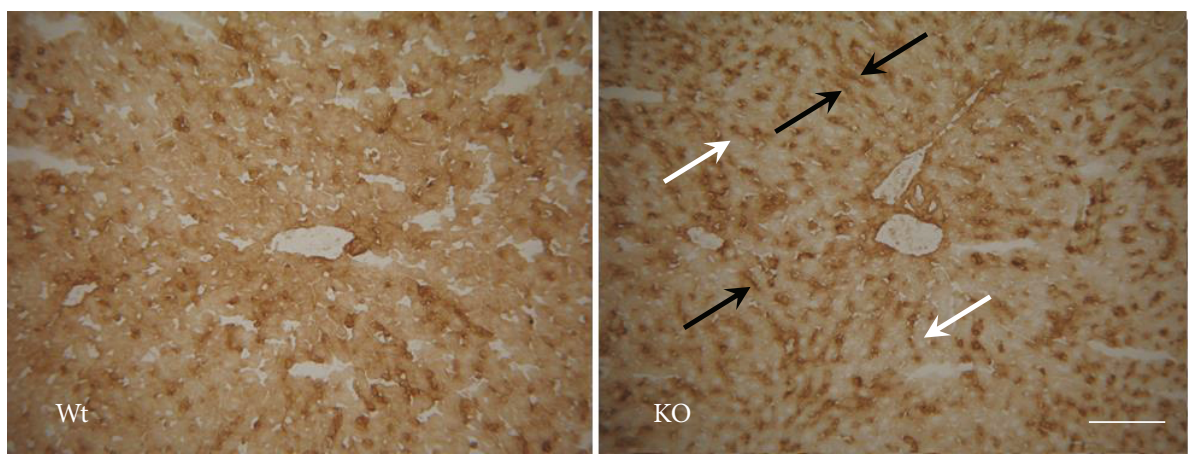

(a)

Ganglioside redistribution to membranes

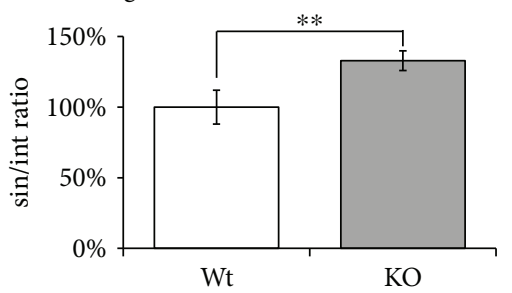

(b)

FIgURE 3: The effect of Hmox1 knockout on distribution/localization of GM1 ganglioside in the liver. (a) Immunohistochemical detection of GM1 ganglioside. In the liver sections, GM1 ganglioside was detected using the cholera toxin B subunit with streptavidin-peroxidase polymer. Diaminobenzidine tetrahydrochloride (brown colour) was used for visualization. The shift of GM1 ganglioside expression from intracellular localization (white arrows) into sinusoidal membranes (black arrows) was observed in Hmox1 knockout animals. (b) Quantification of GM1 staining in the liver. Image analysis of the distribution of GM1 ganglioside staining in the subsinusoidal part of the intracellular compartment (int) and sinusoidal membranes ( $\sin$ ) of hepatocytes, expressed as the sin/int ratio relative to control (Wt). The reaction product was quantified as the mean optical density of the analyzed areas at objective magnification of $40 \mathrm{x}(\mathrm{NA}=0.7)$. Bar represents $100 \mu \mathrm{m}$. Wt: wild-type $(n=6)$; KO: Hmox1 knockout $(n=9) .{ }^{* *} P<0.01$.

$\left.H_{m o x}++, n=6, P=0.032\right)$. No significant increase was observed in a brain tissue $\left(115 \% \pm 46 \% \mathrm{Hmox}^{-1-}, n=7\right.$, vs. $\left.100 \% \pm 45 \% \mathrm{Hmox}^{+/+}, n=6, P=0.311\right)$.

3.2. Hmox1 Knockout Results in Changes in the Expression of Sialyltransferases. Relative mRNA expression of the key sialyltransferases was determined to elucidate the activation rate of $a$ - and $b$-series of a ganglioside biosynthetic pathway in mouse liver and brain homogenates. Hmox1 knockout led to a significant increase in mRNA expression of GM3 synthase $(S T 3 G a l V) \quad(287 \pm 55 \%, \quad P<0.001 ; 183 \pm 41 \%$, $P<0.01)$ in both liver and brain, and GD3 synthase (St8SiaI) $(224 \pm 89 \%, P<0.01)$, the key step in an activation of $b$-biosynthetic branch in the liver. Hmox 1 knockout caused also significant activation of GM2/GD2 synthase (B4GalNTI) $(538 \pm 121 \%, P<0.001)$ in the liver. Expression of GM1 synthase (B3GalTIV) stayed unchanged in both liver and brain (Figure 2).

3.3. Hmox1 Knockout Leads to a Marked Shift of Gangliosides to the Hepatocyte Membrane. To study possible changes in distribution of gangliosides within mouse hepatocytes, histochemical localization of GM1, the representative of gangliosides, was determined in the liver sections. In control liver specimens, GM1 was detected in both sinusoidal and canalicular membranes, as well as in the intracytoplasmic compartment. In Hmox 1 knockout animals, we observed a pronounced shift in GM1 ganglioside expression from intracellular localization into sinusoidal membranes (Figure 3(a)). To quantify this redistribution pattern of GM1, we measured the GM1 expression under high microscopic magnification expressed as sin/int ratio (GM1 staining in the sinusoidal membrane/subsinusoidal intracellular compartment) $(133 \pm 7 \%, P<0.01$, Figure $3(\mathrm{~b}))$.

3.4. Ganglioside Pattern in Neuroblastoma Cells (SH-SY5Y) Is Affected by Oxidative Stress. To find out whether changes in the ganglioside pattern might be affected by an increased oxidative stress associated with Hmoxl knockout, we investigated the regulation of glycosphingolipid (GSL) synthesis using SH-SY5Y neuroblastoma cells rich in gangliosides. CDCA, a potent inducer of ROS production accumulating in the liver during cholestasis, was used to increase oxidative stress in vitro, while addition of bilirubin, a potent antioxidant and a product of the Hmox pathway, had an opposite effect (Figure 4).

Administration of CDCA $(80 \mu \mathrm{M})$ resulted in a significant increase in the major gangliosides GD1a (141\%, $P<0.01)$, GM3 (170\%, $P<0.01)$, and GM2 (130\%, $P<0.05)$ in SH-SY5Y neuroblastoma cells (Figure 5(a)) and GM3 (233\%, $P<0.01)$ and GM2 $(251 \%, P<0.05)$ in hepatoblastoma HepG2 cells (Figure 5(b)). Interestingly, coadministration of bilirubin (CDCA/bilirubin), a potent antioxidant, resulted in normalization of the ganglioside pattern in both cell lines (Figure 5). 


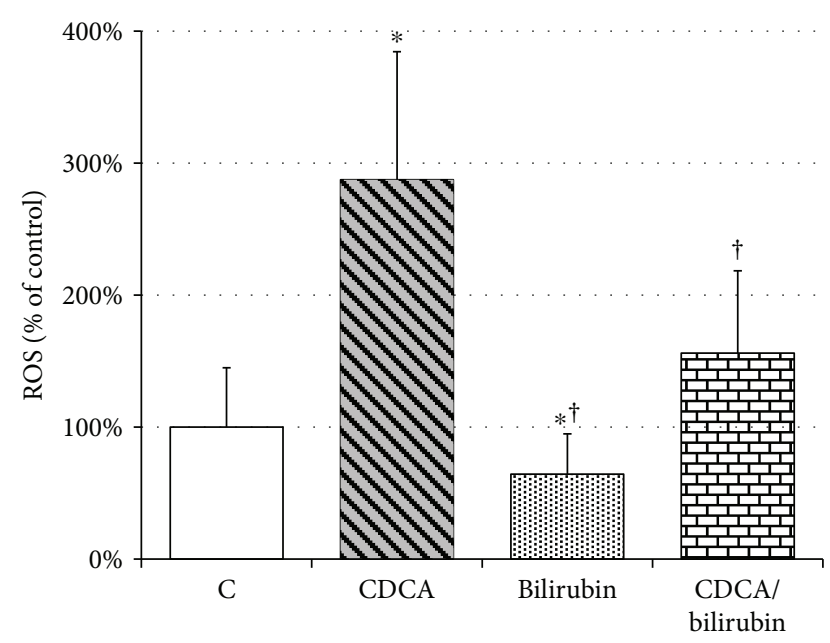

FIGURE 4: The ameliorating effect of bilirubin on CDCA-induced oxidative stress in SH-SY5Y cells. SH-SY5Y cells were incubated with CDCA $(80 \mu \mathrm{M})$, bilirubin $(1 \mu \mathrm{M})$, or both (CDCA/bilirubin) for $24 \mathrm{~h}$. ROS production was measured using fluorescent CM-H2DCFDA probe. Values are expressed as \% of controls. C: control; CDCA: chenodeoxycholic acid $(80 \mu \mathrm{M})$; bilirubin: $1 \mu \mathrm{M}$ bilirubin; CDCA/bilirubin: CDCA $(80 \mu \mathrm{M})+$ bilirubin $(1 \mu \mathrm{M})$. ${ }^{*} P<0.05$ vs. $\mathrm{C} ;{ }^{\dagger} P<0.05$ vs. $\mathrm{CDCA}$.

3.5. Oxidative Stress-Mediated Changes in Sialyltransferase (ST3GalV) Expression Are Regulated through the Protein Kinase C Pathway. To elucidate whether oxidative stress induced by CDCA affects the expression of GM3 synthase (ST3GalV), a key enzyme in ganglioside metabolism, in vitro, SH-SY5Y as well as HepG2 cell lines were incubated with CDCA and/or bilirubin for $4 \mathrm{~h}$. Significant increases in GM3 synthase mRNA expression were observed upon CDCA treatment while cotreatment with bilirubin abolished this effect in both neuroblastoma (Figure 6(a)) and hepatic (Figure 6(c)) cell lines. The results were confirmed by the detection of GM3 synthase protein expression in the SH-SY5Y cell line (Figure 6(b)).

To investigate the possible role of the PKC pathway on oxidative stress-mediated changes in ganglioside expression, we measured the effect of PKC induction/inhibition $\left(\mathrm{PKC}^{+/-}\right)$on the mRNA expression of GM3 synthase (ST3GalV), in the SH-SY5Y cell line. PKC activators induced the mRNA expression of ST3GalV. On the other hand, PKC inhibitors significantly decreased ST3GalV mRNA expression. Importantly, cotreatment of CDCA with PKC inhibitor completely abolished the stimulatory effect of CDCA on ST3GalV mRNA (Figure 6(d)). Successful PKC activation and/or inhibition was proven by determination of mRNA expression of PKC alpha, PKC beta, and PKC epsilon (Figure 6(e)).

\section{Discussion}

Gangliosides play a crucial role in signal transduction pathways, regulating many different cell functions such as proliferation, differentiation, adhesion, and cell death $[32,33]$. They are responsible for the rigidity of a plasmatic membrane [34] and participate in a protection against oxidative stress $[19,21]$. However, the significance of changes in ganglioside metabolism under oxidative stress remains to be elucidated. To address this issue, we have studied the consequences of the antioxidant enzyme Hmoxl deficiency for ganglioside metabolism in mouse tissues. Unlike in the brain, we found significantly increased lipid peroxidation in the liver of Hmox1 knockout animals which is in accordance with the published data showing increased lipid peroxidation and hepatic injury mostly due to iron accumulation in the liver tissue [6]. Our results indicate that oxidative stress plays an important role in ganglioside synthesis resulting in changes in their spectra and cellular distribution.

Gangliosides are ubiquitously found in tissues and body fluid with the most abundant expression in the nervous system [35]. The expression levels of gangliosides undergo dramatic changes during various physiological and pathological conditions including cell death, proliferation, differentiation, development, and oncogenesis [36-38] as well as neurological diseases $[39,40]$. These effects are largely attributed to the changes in expression levels of ganglioside synthases (glycosyltransferases) [41, 42]. In our previous experiments on rats, we observed the shift in liver ganglioside synthesis towards more complex ones in various types of cholestatic liver diseases $[25,30]$. These changes were associated with the accumulation of detergent and prooxidative bile acids as well as with the increase in oxidative stress in these animals $[21,22]$.

In the present study, Hmoxl knockout resulting in the absence of an important antioxidant enzyme in experimental mice was accompanied by significant increases in the brain GM1, GD1a, and GD3 and liver GM1, GM3, and GD1b gangliosides. The tissue specificity of these changes might be explained by the different ganglioside composition of the liver and brain tissues. While GM3 is the main ganglioside in the liver, GD1a is the most abundant in the adult brain $[38,43]$, where GD1a, GM1, GD1b, GT1b, and GD3 belong to most important glycosphingolipids [44]. Several reports suggest gangliosides to possess antioxidant properties, but very little is known about the function of gangliosides in the liver and therefore most data relates to the nervous tissue [11]. Among these, GM1 ganglioside has neuroprotective functions. Micelles containing GM1 inhibited ironcatalysed hydroxyl radical formation in vitro [18], GM1 decreased ROS formation in rat brain synaptosomes [45], or protected cells against $\mathrm{H}_{2} \mathrm{O}_{2}$-induced oxidative damage [46] while GD1b was able to inhibit lipid peroxidation in human sperm cells [47]. On the other hand, some gangliosides might enhance ROS formation and contribute to the cell death. Sohn et al. [48] found GM3, but not GD3 or GT1b, to mediate oxidative toxicity induced by glutamate in immortalized mouse neuronal HT22 cells. GD3 was described to interact with mitochondria and generate $\operatorname{ROS}[49,50]$, and there is strong evidence for involvement of GD3 in autophagosome formation [51, 52]. GD3 is also considered a key player in apoptosis by Fas, ceramide, and amyloid- $\beta$ [53, 54]. These findings suggest an important role of gangliosides in processes involved in oxidative stress regulation which might explain their compensatory upregulation in the prooxidative environment of Hmox1 knockout. 

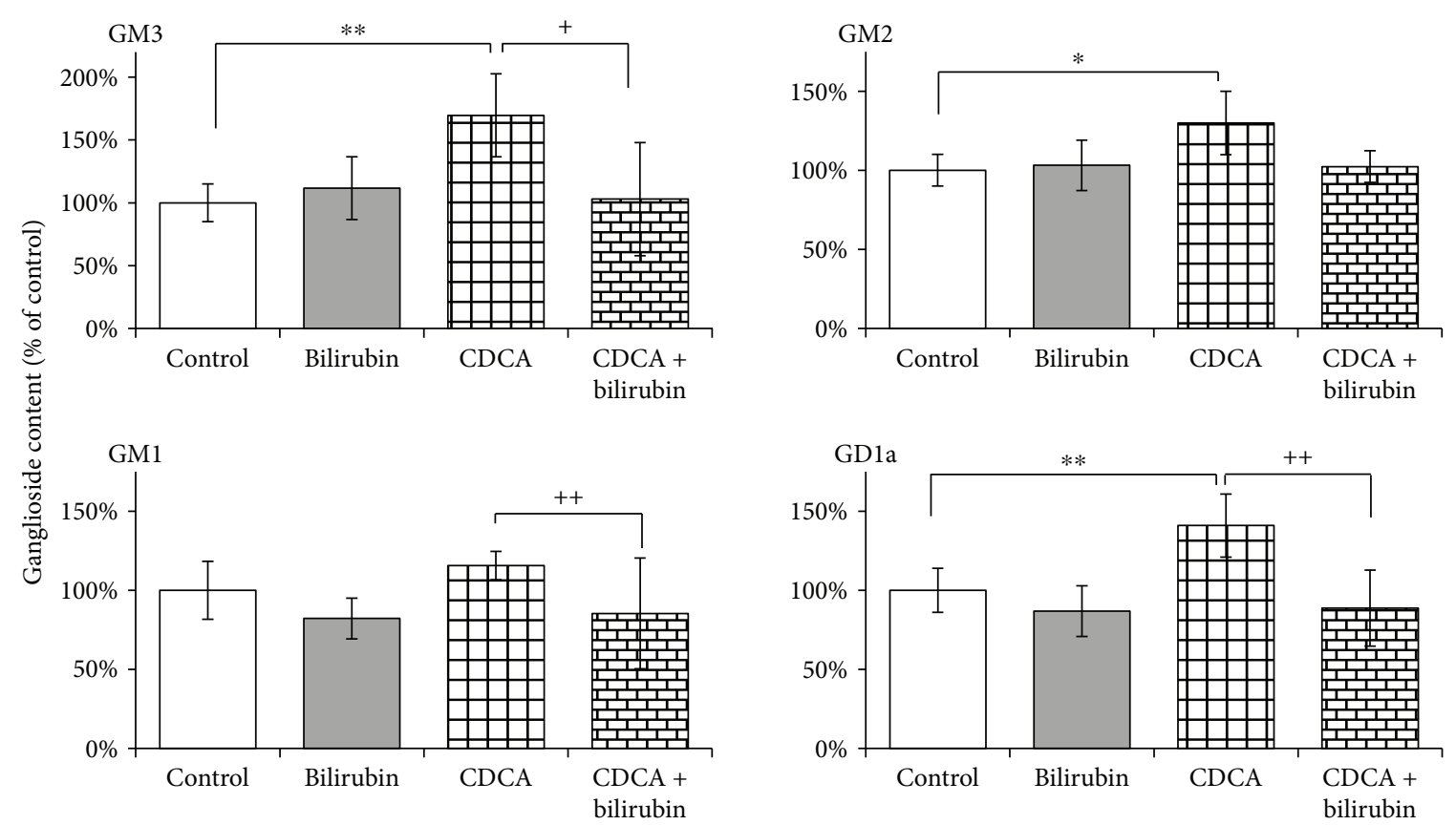

(a)
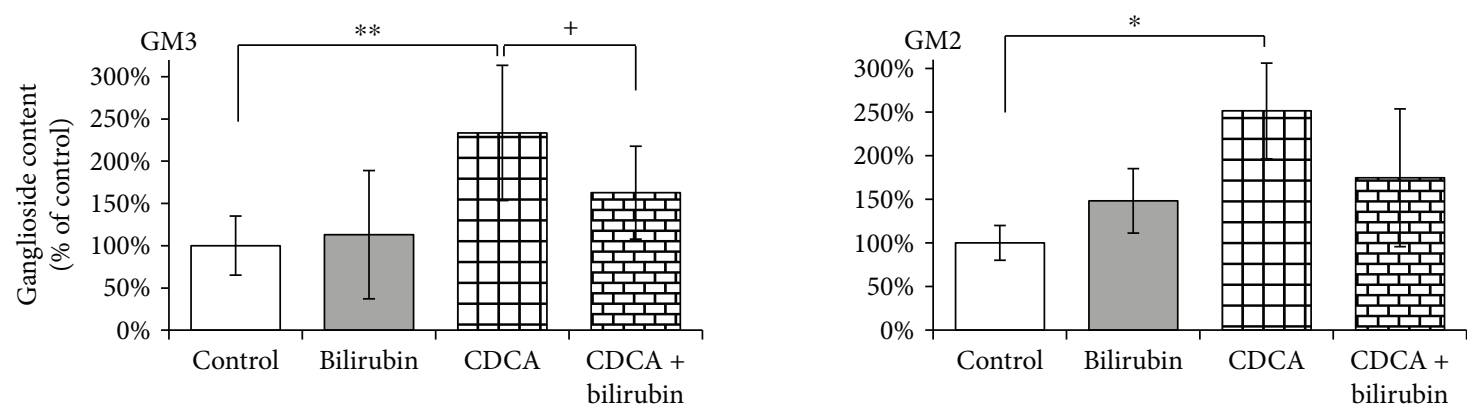

(b)

Figure 5: The ameliorating effect of bilirubin on CDCA-induced change in ganglioside content in SH-SY5Y cells (a) and HepG2 cells (b). Relative content of individual gangliosides was evaluated using extraction and TLC densitometry after incubation with CDCA or CDCA/ bilirubin for 4 in (a) SH-SY5Y cells and (b) HepG2 cells. Values are expressed as \% of controls. Bilirubin ( $1 \mu \mathrm{M})$; CDCA: chenodeoxycholic acid $(80 \mu \mathrm{M})$; CDCA/bilirubin: $\mathrm{CDCA}(80 \mu \mathrm{M})+\operatorname{bilirubin}(1 \mu \mathrm{M}) .{ }^{*} P<0.05$ vs. C; ${ }^{* *} P<0.01$ vs. $\mathrm{C} ;{ }^{+} P<0.05$ vs. CDCA; ${ }^{++} P<0.01$ vs. CDCA.

The effect of oxidative stress on changes in ganglioside synthesis was further supported by determination of glycosyltransferase mRNA expressions in mouse liver and brain homogenates. The key regulatory enzymes in the synthesis of nearly all gangliosides, GM3 and GD3 synthases, as well as GalNAcT, were found to be significantly increased in Hmox1 knockouts while GM1 synthase expression stayed unchanged. These data correspond with the observed increases in liver gangliosides and are in accordance with our previous observations on liver glycosyltransferase expression in experimental cholestasis in rats [22]. The increase in liver GM1 ganglioside content in Hmoxl knockouts allows speculating that expression of GM1 synthase is redundant in wild-type animals and is capable of maintaining the induction of the GalNAcT product. Interestingly, only GM3 synthase has been found to be significantly upregulated in the brain suggesting the tissue-specific regulation of various sialyltransferases. Moreover, different extents of oxidative stress in particular tissues might affect the final sialyltransferase expression.

Furthermore, in our earlier reports, we described not only an increase in ganglioside synthesis but also their shift into the sinusoidal membranes of hepatocytes upon oxidative stress induced by bile acids [21]. This mechanism could protect hepatocytes against detergent and prooxidant effects of bile acids. A very similar effect was observed in the present study. We have used a selective histochemical approach based on the high binding affinity of Cholera toxin B subunit to GM1 ganglioside [6], the representative of the complex gangliosides. A significant shift of GM1 gangliosides from intracellular localization to the membrane compartment was found in Hmoxl knockout which is also associated with prooxidative condition.

To investigate the mechanism of oxidative stressmediated changes in ganglioside metabolism, we used the in vitro model of the SH-SY5Y neuroblastoma cell line rich 


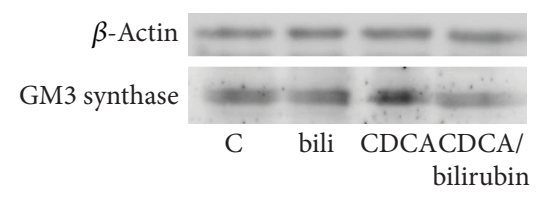

GM3 synthase (SH-SY5Y)

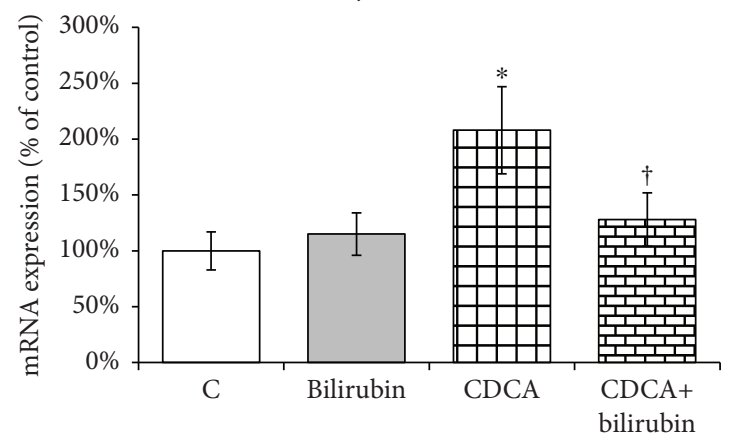

(a)

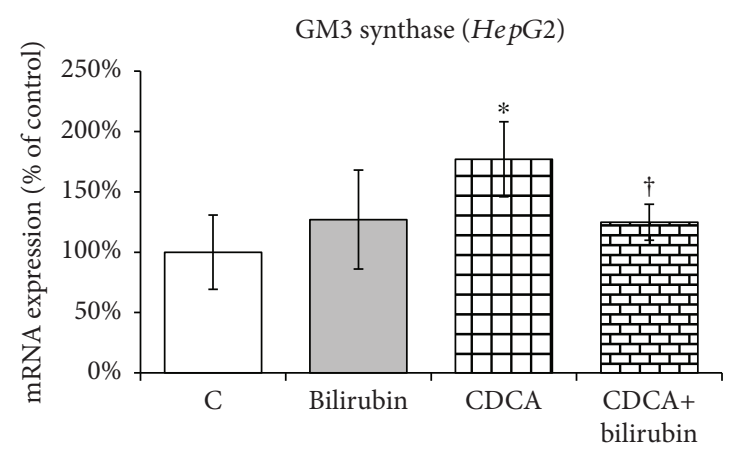

(c)

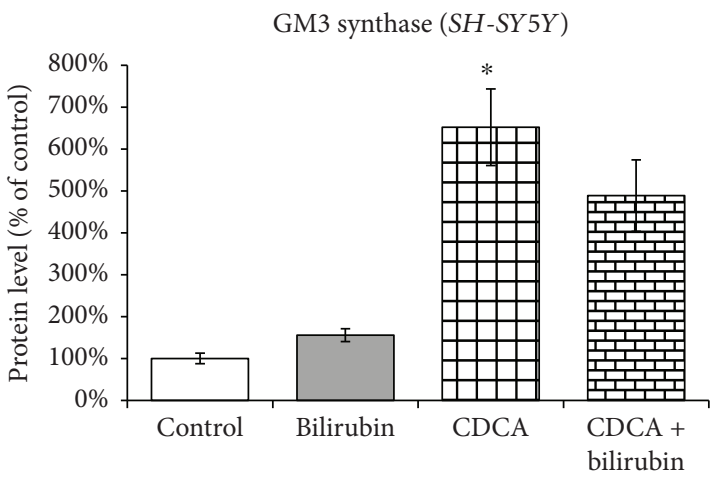

(b)

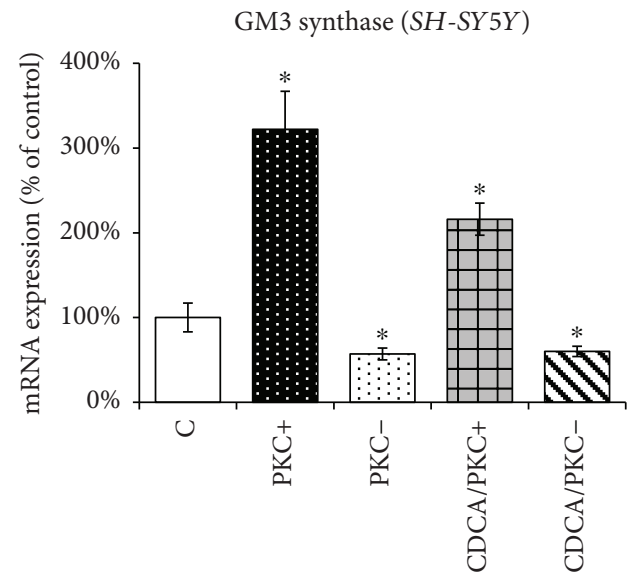

(d)

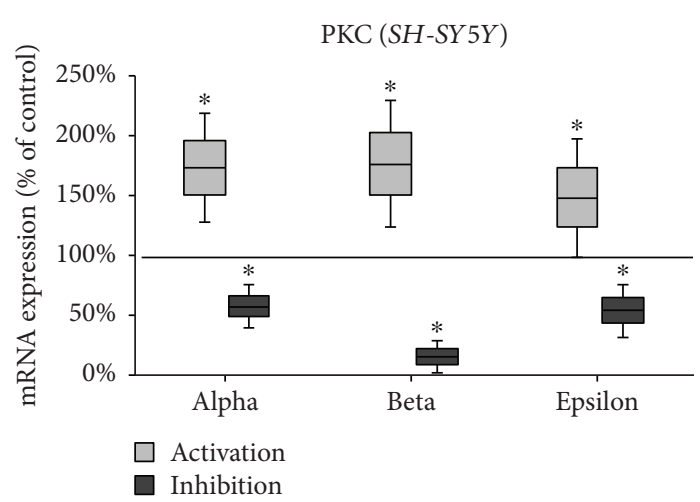

(e)

FIGURE 6: The opposite effects of CDCA and bilirubin on regulation of GM3 synthase expression in SH-SY5Y and HepG2 cells. (a) Relative GM3 synthase (ST3GalV) mRNA expression was determined in control cells (C), after $4 \mathrm{~h}$ incubation with chenodeoxycholic acid (CDCA) and/or bilirubin in SH-SY5Y cells. (b) Relative GM3 synthase (ST3GalV) protein expression by Western blot was determined in control cells (C), after $4 \mathrm{~h}$ incubation with chenodeoxycholic acid (CDCA) and/or bilirubin in SH-SY5Y cells. (c) Relative GM3 synthase (ST3GalV) mRNA expression was determined in control cells (C), after $4 \mathrm{~h}$ incubation with chenodeoxycholic acid (CDCA) and/or bilirubin in HepG2 cells. (d) PKC activity was modulated by incubating SH-SY5Y cells with PKC activator $\left(\mathrm{PKC}^{+}\right)$or $\mathrm{PKC}$ inhibitor $\left(\mathrm{PKC}^{-}\right)$or their combination with CDCA (CDCA/PKC ${ }^{+}, \mathrm{CDCA} / \mathrm{PKC}^{-}$) for $4 \mathrm{~h}$. (e) $\mathrm{PKC}$ activation and/or inhibition was proven by determination of mRNA expression vs. control (100\% line) of PKC alpha, PKC beta, and PKC epsilon in SH-SY5Y cells. Values are expressed as \% of controls. C: control; $\mathrm{PKC}^{+}$: PKC activation by phorbol 12 -myristate 13 -acetate $(5 \mu \mathrm{M})$; $\mathrm{PKC}^{-}$: PKC inhibition by Ro $31-0432(5 \mu \mathrm{M})$; CDCA: chenodeoxycholic acid $(80 \mu \mathrm{M})$; CDCA/bilirubin: CDCA $(80 \mu \mathrm{M})+$ bilirubin $(1 \mu \mathrm{M}) .{ }^{*} P<0.05$ vs. C; ${ }^{\dagger} P<0.05$ vs. CDCA. 
in glycosphingolipids and, for the comparison, the human hepatoblastoma HepG2 cell line. Interestingly, the HepG2 cell line was found to be very poor in ganglioside content and completely lacking GD3 synthase. Exposure of SH-SY5Y to oxidative stress induced by chenodeoxycholic acid [55] resulted in a significant increase in all major gangliosides of this cell line-GD1a, GM3, and GM2-while addition of a potent antioxidant, bilirubin [56], resulted in normalization of the ganglioside content. Importantly, the same pattern was observed in the HepG2 cell line in GM3 and GM2 gangliosides. These results are in accordance with our earlier observations [10] that bilirubin may counteract a prooxidative effect of BA on hepatocytes in the model of obstructive cholestasis in rats. Furthermore, accumulation of hydrophobic BA in the brain and their possible involvement in hepatic encephalopathy associated with cholestatic liver diseases has been reported [57]. BA can act as cell signalling effectors through binding and activating receptors on both the cell membrane and nucleus. BA signalling encompasses both direct (FXR, TGR5) and indirect (FGF19, GLP-1) pathways. The role of BA in extrahepatic diseases is becoming more important, and increasing amount of reports suggests that BA might play an important role in neurological function and diseases [58, 59].

To elucidate the mechanism of oxidative stress-induced changes of ganglioside metabolism, we focused on regulation of the main enzyme in complex ganglioside synthesis, GM3 synthase (ST3GalV).

PKC appeared to be a logical candidate regulating the expression of GM3 synthase. Hydrophobic bile acids are considered potent inducers of PKC while antioxidants inhibit PKC activity $[60,61]$. For more than 30 years, it has been known that ganglioside metabolism is in tight connection to PKC activity [62-64], and the action of glycosyltransferases is controlled through posttranslational modification. Glycosyltransferase activities have been demonstrated to be significantly modulated by the action of PKC [65]. Another study suggested the role of PKC as an activator of GM3 synthase (ST3GalV) [66]. Our in vitro data support this hypothesis. While PKC activators and oxidative stress induced the expression of ST3GalV, PKC inhibitors as well as antioxidants completely abolished this effect.

There are some limitations of our study. First, we were primarily interested in the shift of GSL to the cytoplasmic membrane; however, more studies are needed to assess whether subcellular localization and trafficking of gangliosides are affected as well. Second, in histochemical analyses, we used GM1 as a GSL representative but further studies with individual gangliosides are needed to confirm that the shift of GM1 from the intracellular compartment to the cytoplasmic membrane is a general reaction to loss of Hmoxl action. Finally, the PKC pathway is an important but probably not the only pathway regulating GSL metabolism affected by oxidative stress.

\section{Conclusions}

We conclude that oxidative stress is an important factor modulating synthesis and distribution of gangliosides in vivo and in vitro. Knockout of Hmoxl, an important antioxidant enzyme, results in tissue-specific increases in main gangliosides together with changes in mRNA expression of key enzymes of ganglioside synthesis. We demonstrate that these changes might be, at least partially, mediated through modulation of the PKC pathway.

\section{Data Availability}

The raw data used to support the findings of this study are available from the corresponding author upon request.

\section{Conflicts of Interest}

The authors declare that there is no conflict of interest regarding the publication of this paper.

\section{Acknowledgments}

The study was supported by Grant RVO-VFN64165/2018 given by the Czech Ministry of Health; PROGRES Q25/ LF1, GAUK 516912, and SVV 260370-2017 provided by the Charles University, Prague, Czech Republic; and the statutory funds from the Jagiellonian University. The Faculty of Biochemistry, Biophysics and Biotechnology of Jagiellonian University is a partner of the Leading National Research Centre (KNOW) supported by the Ministry of Science and Higher Education. The authors wish to thank Janusz Drebot and Witold Nowak for their help with the animal experiments, Kateřina Žížalová for her help with cell culture experiments, and Olga Švejdová and Marie Kolářová for their excellent technical assistance.

\section{References}

[1] L. E. Otterbein, M. P. Soares, K. Yamashita, and F. H. Bach, "Heme oxygenase-1: unleashing the protective properties of heme," Trends in Immunology, vol. 24, no. 8, pp. 449-455, 2003.

[2] P. Ayuso, C. Martínez, P. Pastor et al., "An association study between Heme oxygenase-1 genetic variants and Parkinson's disease," Frontiers in Cellular Neuroscience, vol. 8, p. 298, 2014.

[3] H. Schipper and W. Song, "A heme oxygenase-1 transducer model of degenerative and developmental brain disorders," International Journal of Molecular Sciences, vol. 16, no. 12, pp. 5400-5419, 2015.

[4] L.E. Fredenburgh, A. A. Merz, and S. Cheng, "Haeme oxygenase signalling pathway: implications for cardiovascular disease," European Heart Journal, vol. 36, no. 24, pp. 1512-1518, 2015.

[5] K. D. Poss and S. Tonegawa, "Reduced stress defense in heme oxygenase 1-deficient cells," Proceedings of the National Academy of Sciences of the United States of America, vol. 94, no. 20, pp. 10925-10930, 1997.

[6] S. T. Fraser, R. G. Midwinter, B. S. Berger, and R. Stocker, "Heme oxygenase-1: a critical link between iron metabolism, erythropoiesis, and development," Advances in Hematology, vol. 2011, Article ID 473709, 6 pages, 2011.

[7] T. Mamiya, F. Katsuoka, A. Hirayama et al., "Hepatocytespecific deletion of heme oxygenase-1 disrupts redox homeostasis in basal and oxidative environments," The Tohoku Journal of Experimental Medicine, vol. 216, no. 4, pp. 331-339, 2008. 
[8] L. Novotny and L. Vitek, "Inverse relationship between serum bilirubin and atherosclerosis in men: a meta-analysis of published studies," Experimental Biology and Medicine, vol. 228, no. 5, pp. 568-571, 2003.

[9] J. Zelenka, L. Muchova, M. Zelenkova et al., "Intracellular accumulation of bilirubin as a defense mechanism against increased oxidative stress," Biochimie, vol. 94, no. 8, pp. 1821-1827, 2012.

[10] L. Muchova, K. Vanova, J. Zelenka et al., "Bile acids decrease intracellular bilirubin levels in the cholestatic liver: implications for bile acid-mediated oxidative stress," Journal of Cellular and Molecular Medicine, vol. 15, no. 5, pp. 1156-1165, 2011.

[11] R. K. Yu, Y. Nakatani, and M. Yanagisawa, "The role of glycosphingolipid metabolism in the developing brain," Journal of Lipid Research, vol. 50, pp. S440-S445, 2009.

[12] A. Regina Todeschini and S. I. Hakomori, "Functional role of glycosphingolipids and gangliosides in control of cell adhesion, motility, and growth, through glycosynaptic microdomains," Biochimica et Biophysica Acta (BBA) - General Subjects, vol. 1780, no. 3, pp. 421-433, 2008.

[13] H. Rahmann, "Brain gangliosides and memory formation," Behavioural Brain Research, vol. 66, no. 1-2, pp. 105-116, 1995.

[14] B. Wang, "Sialic acid is an essential nutrient for brain development and cognition," Annual Review of Nutrition, vol. 29, no. 1, pp. 177-222, 2009.

[15] L. J. Pike, "Rafts defined: a report on the keystone symposium on lipid rafts and cell function," Journal of Lipid Research, vol. 47, no. 7, pp. 1597-1598, 2006.

[16] D. Lingwood and K. Simons, "Lipid rafts as a membraneorganizing principle," Science, vol. 327, no. 5961, pp. 46-50, 2010.

[17] J. Taira, M. Sugishima, Y. Kida, E. Oda, M. Noguchi, and Y. Higashimoto, "Caveolin-1 is a competitive inhibitor of heme oxygenase-1 (HO-1) with heme: identification of a minimum sequence in caveolin-1 for binding to $\mathrm{HO}-1$," Biochemistry, vol. 50, no. 32, pp. 6824-6831, 2011.

[18] M. Gavella, M. Kveder, V. Lipovac, D. Jurašin, and N. Filipovi-Vinceković, "Antioxidant properties of ganglioside micelles," Free Radical Research, vol. 41, no. 10, pp. 1143-1150, 2007.

[19] M. Gavella, M. Kveder, and V. Lipovac, "Modulation of ROS production in human leukocytes by ganglioside micelles," Brazilian Journal of Medical and Biological Research, vol. 43, no. 10, pp. 942-949, 2010.

[20] N. F. Avrova, I. V. Victorov, V. A. Tyurin et al., "Inhibition of glutamate-induced intensification of free radical reactions by gangliosides: possible role in their protective effect in rat cerebellar granule cells and brain synaptosomes," Neurochemical Research, vol. 23, no. 7, pp. 945-952, 1998.

[21] T. Petr, V. Smíd, V. Kučerová et al., “The effect of heme oxygenase on ganglioside redistribution within hepatocytes in experimental estrogen-induced cholestasis," Physiological Research, vol. 63, no. 3, pp. 359-367, 2014.

[22] V. Šmíd, T. Petr, K. Váňová et al., "Changes in liver ganglioside metabolism in obstructive cholestasis - the role of oxidative stress," Folia Biologica, vol. 62, no. 4, pp. 148-159, 2016.

[23] A. Szade, W. N. Nowak, K. Szade et al., "Effect of crossing C57BL/6 and FVB mouse strains on basal cytokine expression," Mediators of Inflammation, vol. 2015, Article ID 762419, 10 pages, 2015.
[24] P. W. Hamilton, "Designing a morphometric study," in Quantitative Clinical Pathology, P. W. Hamilton and D. C. Allen, Eds., Blackwell Science, Cambridge, MA, USA, 1995.

[25] F. Majer, L. Trnka, L. Vítek, M. Jirkovská, Z. Mareček, and F. Šmíd, "Estrogen-induced cholestasis results in a dramatic increase of b-series gangliosides in the rat liver," Biomedical Chromatography, vol. 21, no. 5, pp. 446-450, 2007.

[26] R. K. Yu and R. W. Ledeen, "Gangliosides of human, bovine, and rabbit plasma," Journal of Lipid Research, vol. 13, no. 5, pp. 680-686, 1972.

[27] K. Suzuki, "The pattern of mammalian brain gangliosides-II evaluation of the extraction procedures, postmortem changes and the effect of formalin preservation," Journal of Neurochemistry, vol. 12, no. 7, pp. 629-638, 1965.

[28] J. Folch, M. Lees, and G. H. Sloane Stanley, “A simple method for the isolation and purification of total lipides from animal tissues," The Journal of Biological Chemistry, vol. 226, no. 1, pp. 497-509, 1957.

[29] M. A. Chester, "IUPAC-IUB Joint Commission on Biochemical Nomenclature (JCBN). Nomenclature of glycolipids-recommendations 1997," European Journal of Biochemistry, vol. 257, no. 2, pp. 293-298, 1998.

[30] M. Jirkovská, F. Majer, J. Šmídová et al., "Changes in GM1 ganglioside content and localization in cholestatic rat liver," Glycoconjugate Journal, vol. 24, no. 4-5, pp. 231-241, 2007.

[31] H. J. Vreman, R. J. Wong, C. A. Sanesi, P. A. Dennery, and D. K. Stevenson, "Simultaneous production of carbon monoxide and thiobarbituric acid reactive substances in rat tissue preparations by an iron-ascorbate system," Canadian Journal of Physiology and Pharmacology, vol. 76, no. 12, pp. 1057$1065,1998$.

[32] S. Hakomori, "Carbohydrate-to-carbohydrate interaction, through glycosynapse, as a basis of cell recognition and membrane organization," Glycoconjugate Journal, vol. 21, no. 3/4, pp. 125-137, 2004.

[33] R. L. Schnaar, "Glycolipid-mediated cell-cell recognition in inflammation and nerve regeneration," Archives of Biochemistry and Biophysics, vol. 426, no. 2, pp. 163-172, 2004.

[34] I. Pascher, M. Lundmark, P. G. Nyholm, and S. Sundell, "Crystal structures of membrane lipids," Biochimica et Biophysica Acta (BBA) - Reviews on Biomembranes, vol. 1113, no. 3-4, pp. 339-373, 1992.

[35] R. K. Yu, Y. T. Tsai, and T. Ariga, "Functional roles of gangliosides in neurodevelopment: an overview of recent advances," Neurochemical Research, vol. 37, no. 6, pp. 1230-1244, 2012.

[36] S. Hakomori, "Structure, organization, and function of glycosphingolipids in membrane," Current Opinion in Hematology, vol. 10, no. 1, pp. 16-24, 2003.

[37] M. Bektas and S. Spiegel, "Glycosphingolipids and cell death," Glycoconjugate Journal, vol. 20, no. 1, pp. 39-47, 2004.

[38] S. Ngamukote, M. Yanagisawa, T. Ariga, S. Ando, and R. K. $\mathrm{Yu}$, "Developmental changes of glycosphingolipids and expression of glycogenes in mouse brains," Journal of Neurochemistry, vol. 103, no. 6, pp. 2327-2341, 2007.

[39] Y. H. Xu, S. Barnes, Y. Sun, and G. A. Grabowski, "Multisystem disorders of glycosphingolipid and ganglioside metabolism," Journal of Lipid Research, vol. 51, no. 7, pp. 1643-1675, 2010.

[40] S. Lobasso, P. Tanzarella, D. Vergara, M. Maffia, T. Cocco, and A. Corcelli, "Lipid profiling of parkin-mutant human skin 
fibroblasts," Journal of Cellular Physiology, vol. 232, no. 12, pp. 3540-3551, 2017.

[41] A. Ishii, T. Ikeda, S. Hitoshi et al., "Developmental changes in the expression of glycogenes and the content of N-glycans in the mouse cerebral cortex," Glycobiology, vol. 17, no. 3, pp. 261-276, 2007.

[42] Y. Suzuki, M. Yanagisawa, T. Ariga, and R. K. Yu, "Histone acetylation-mediated glycosyltransferase gene regulation in mouse brain during development," Journal of Neurochemistry, vol. 116, no. 5, pp. 874-880, 2011.

[43] A. Yamamoto, M. Haraguchi, S. Yamashiro et al., "Heterogeneity in the expression pattern of two ganglioside synthase genes during mouse brain development," Journal of Neurochemistry, vol. 66, no. 1, pp. 26-34, 1996.

[44] H. Dreyfus, B. Guérold, L. Freysz, and D. Hicks, "Successive isolation and separation of the major lipid fractions including gangliosides from single biological samples," Analytical Biochemistry, vol. 249, no. 1, pp. 67-78, 1997.

[45] N. F. Avrova, I. O. Zakharova, V. A. Tyurin, Y. Y. Tyurina, I. A. Gamaley, and I. A. Schepetkin, "Different metabolic effects of ganglioside GM1 in brain synaptosomes and phagocytic cells," Neurochemical Research, vol. 27, no. 7/8, pp. 751-759, 2002.

[46] I. A. Vlasova, I. O. Zakharova, T. V. Sokolova, and N. F. Avrova, "Metabolic effects of ganglioside GM1 on PC12 cells at oxidative stress depend on modulation of activity of tyrosine kinase of trk receptor," Zhurnal Evoliutsionno i Biokhimii $i$ Fiziologii, vol. 49, no. 1, pp. 15-23, 2013.

[47] M. Gavella, V. Lipovac, R. Rakos, and B. Colak, "Reduction of oxidative changes in human spermatozoa by exogenous gangliosides," Andrologia, vol. 37, no. 1, pp. 17-24, 2005.

[48] H. Sohn, Y. S. Kim, H. T. Kim et al., "Ganglioside GM3 is involved in neuronal cell death," The FASEB Journal, vol. 20, no. 8, pp. 1248-1250, 2006.

[49] C. García-Ruiz, A. Colell, R. París, and J. C. Fernández-Checa, "Direct interaction of GD3 ganglioside with mitochondria generates reactive oxygen species followed by mitochondrial permeability transition, cytochrome $c$ release, and caspase activation," The FASEB Journal, vol. 14, no. 7, pp. 847-858, 2000.

[50] M. R. Rippo, F. Malisan, L. Ravagnan et al., "GD3 ganglioside directly targets mitochondria in a bcl-2-controlled fashion," The FASEB Journal, vol. 14, no. 13, pp. 2047-2054, 2000.

[51] M. R. Rippo, F. Malisan, L. Ravagnan et al., "GD3 ganglioside as an intracellular mediator of apoptosis," European Cytokine Network, vol. 11, no. 3, pp. 487-488, 2000.

[52] P. Matarrese, T. Garofalo, V. Manganelli et al., "Evidence for the involvement of GD3 ganglioside in autophagosome formation and maturation," Autophagy, vol. 10, no. 5, pp. 750-765, 2014.

[53] F. Malisan and R. Testi, "The ganglioside GD3 as the Greek goddess Hecate: several faces turned towards as many directions," IUBMB Life, vol. 57, no. 7, pp. 477-482, 2005.

[54] A. Dhanushkodi and M. P. McDonald, "Intracranial $V$. cholerae sialidase protects against excitotoxic neurodegeneration," PLoS One, vol. 6, no. 12, article e29285, 2011.

[55] L. Fuentes-Broto, E. Martínez-Ballarín, J. Miana-Mena et al., "Lipid and protein oxidation in hepatic homogenates and cell membranes exposed to bile acids," Free Radical Research, vol. 43, no. 11, pp. 1080-1089, 2009.

[56] L. Vitek and J. Ostrow, "Bilirubin chemistry and metabolism; harmful and protective aspects," Current Pharmaceutical Design, vol. 15, no. 25, pp. 2869-2883, 2009.
[57] V. Tripodi, M. Contin, M. A. Fernández, and A. Lemberg, "Bile acids content in brain of common duct ligated rats," Annals of Hepatology, vol. 11, no. 6, pp. 930-934, 2012.

[58] M. McMillin and S. DeMorrow, "Effects of bile acids on neurological function and disease," The FASEB Journal, vol. 30, no. 11 , pp. $3658-3668,2016$.

[59] K. L. Mertens, A. Kalsbeek, M. R. Soeters, and H. M. Eggink, "Bile acid signaling pathways from the enterohepatic circulation to the central nervous system," Front Neurosci, vol. 11, p. 617, 2017.

[60] Y. P. Rao, R. T. Stravitz, Z. R. Vlahcevic, E. C. Gurley, J. J. Sando, and P. B. Hylemon, "Activation of protein kinase C alpha and delta by bile acids: correlation with bile acid structure and diacylglycerol formation," Journal of Lipid Research, vol. 38, no. 12, pp. 2446-2454, 1997.

[61] S. F. Steinberg, "Mechanisms for redox-regulation of protein kinase C," Front Pharmacol, vol. 6, p. 128, 2015.

[62] D. Kreutter, J. Y. Kim, J. R. Goldenring et al., "Regulation of protein kinase C activity by gangliosides," Journal of Biological Chemistry, vol. 262, no. 4, pp. 1633-1637, 1987.

[63] X. J. Xia, X. B. Gu, A. C. Sartorelli, and R. K. Yu, "Effects of inducers of differentiation on protein kinase $\mathrm{C}$ and CMP-Nacetylneuraminic acid:lactosylceramide sialyltransferase activities of HL-60 leukemia cells," Journal of Lipid Research, vol. 30, no. 2, pp. 181-188, 1989.

[64] J. Aguilera, C. Padrós-Giralt, W. H. Habig, and E. Yavin, "GT1b ganglioside prevents tetanus toxin-induced protein kinase $\mathrm{C}$ activation and down-regulation in the neonatal brain in vivo," Journal of Neurochemistry, vol. 60, no. 2, pp. 709-713, 1993.

[65] R. K. Yu and E. Bieberich, "Regulation of glycosyltransferases in ganglioside biosynthesis by phosphorylation and dephosphorylation," Molecular and Cellular Endocrinology, vol. 177, no. 1-2, pp. 19-24, 2001.

[66] T. W. Chung, H. J. Choi, Y. C. Lee, and C. H. Kim, "Molecular mechanism for transcriptional activation of ganglioside GM3 synthase and its function in differentiation of HL-60 cells," Glycobiology, vol. 15, no. 3, pp. 233-244, 2005. 


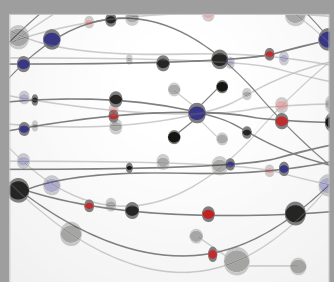

The Scientific World Journal
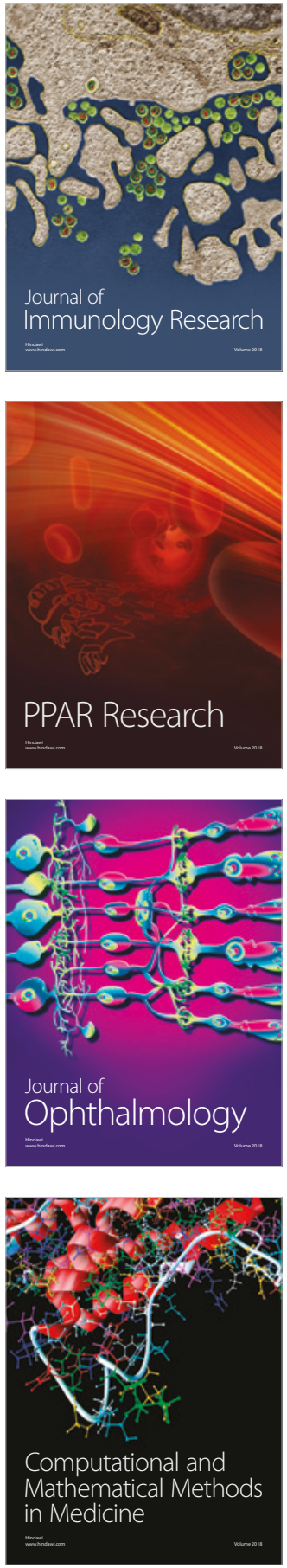

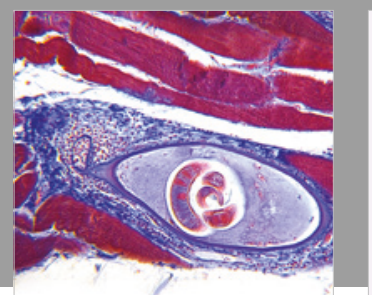

Gastroenterology Research and Practice

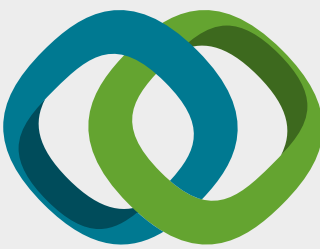

\section{Hindawi}

Submit your manuscripts at

www.hindawi.com
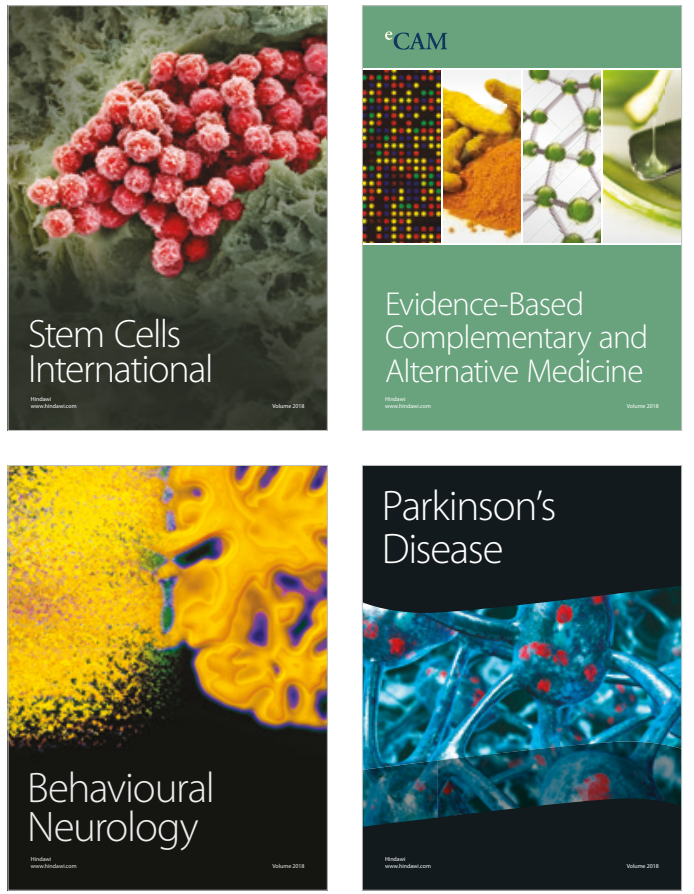

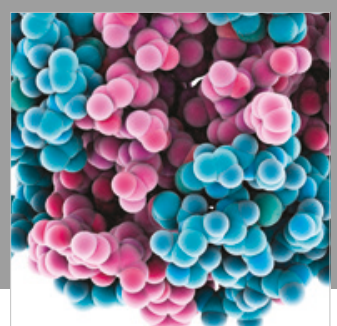

ournal of

Diabetes Research

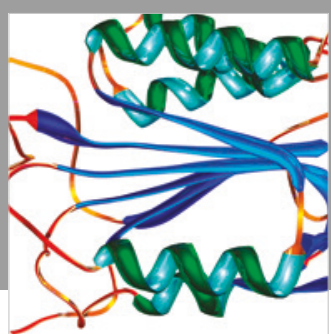

Disease Markers
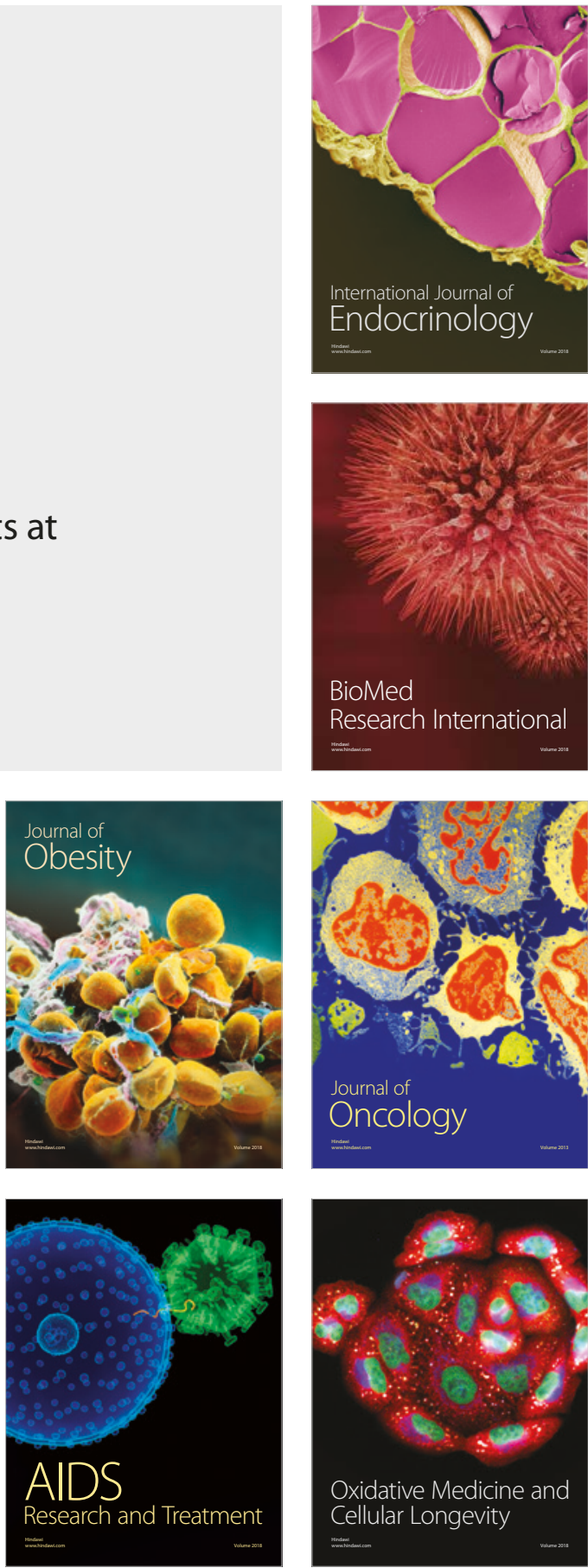